\title{
One-pot Synthesis of Trifunctional Epoxy Resin and its Nanocomposite: Investigation of Thermal and Rheological Properties
}

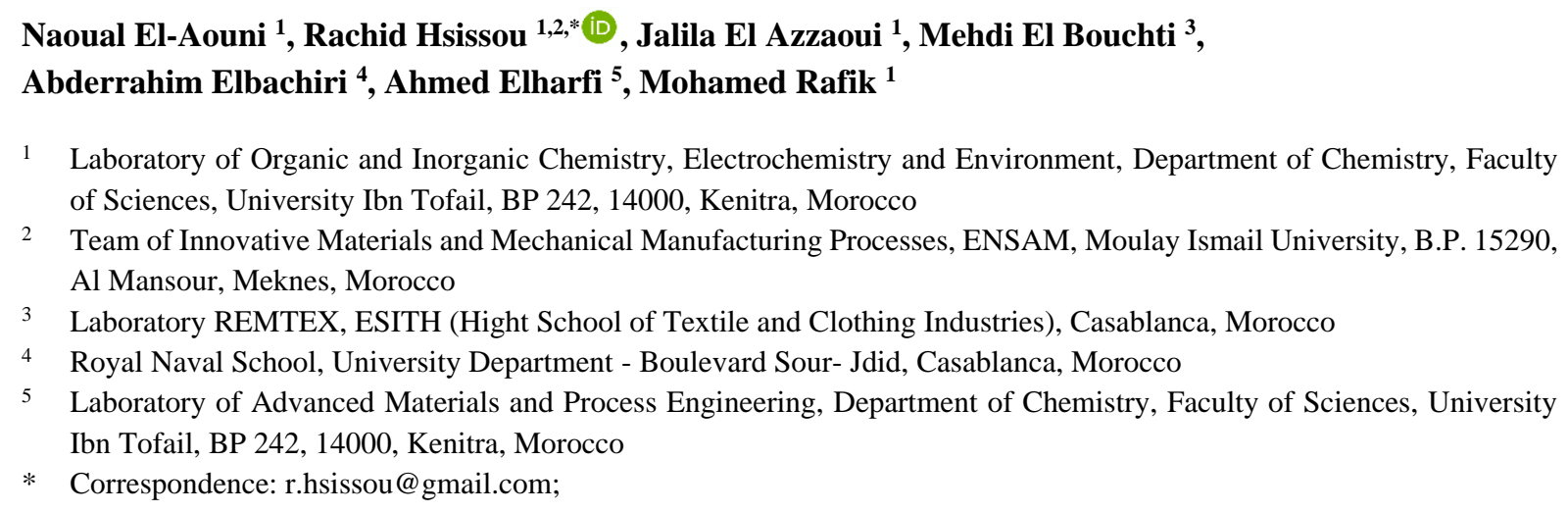

Received: 2.12.2020; Revised: 28.12.2020; Accepted: 2.01.2021; Published: 4.01.2021

\begin{abstract}
Herein, in the present study, we developed the synthesis of new trifunctional epoxy resin (TER) namelytriglycidyl ether N,N bis (3-phenylamino propyl) 3-phenylamino propoxy phenyl and the elaboration of its nanocomposite. TER was characterized and confirmed using Fourier transform infrared and nuclear magnetic resonance spectroscopy. Further, the storage modulus and loss modulus for all formulated nanocomposite increase with the increase in the zinc oxide filler. The results of the thermogravimetric analysis confirm the amelioration in the thermal properties of different nanocomposites TER/MDA/ZnO crosslinked by methylene dianiline (MDA) and formulated by zinc oxide $(\mathrm{ZnO})$ as a filler at varying mass percentage $(0,0.5,1$, and $2 \%)$.
\end{abstract}

Keywords: synthesis; epoxy resin; nanocomposite; rheological; thermogravimetric analysis.

(c) 2020 by the authors. This article is an open-access article distributed under the terms and conditions of the Creative Commons Attribution (CC BY) license (https://creativecommons.org/licenses/by/4.0/).

\section{Introduction}

Epoxy resins are widely used and employed in several industrial application fields such as aerospace, automotive, encapsulate electrical and electronic components [1-4]. Epoxy resins thermosetting are the most commonly used owing to their excellent thermal and mechanical properties and their exceptional anticorrosive coatings properties [5-10]. However, some current problems in the thermosetting resins applications are low stiffness and strength, as well as exothermic heat generated by the curing of epoxy resins. Then, additives are often employed to modify materials' characteristics and properties, including diluents, loads, modifiers, flame retardants, antioxidants, or plasticizers [11-17]. Several researchers have currently adopted that the addition of zinc oxide compound in the epoxy resin matrix exhibits high flame retardancy and thermal stability [18-22]. Further, liquid crystal epoxy resins are widely investigated because of their unusual mechanical and thermal properties, little shrinkage in curing, low thermal expansion coefficient, and dielectric constant [23-27]. The advanced applications of epoxy resins are not alone very demanding, but many new applications with new performance 
requirements are developed every year [28-32]. In addition, the rheological properties of epoxy resins and their nanocomposites are very interesting. The incorporation of zinc oxide as a charge in elaborated nanocomposites could be increasing the storage modulus and the loss modulus. Also, the increase of storage modulus and the loss modulus depends on the dispersion of filler addition into formulated nanocomposite [33-38]. In this potential study, we synthesized and developed the triglycidyl ether N,N bis (3-phenylamino propyl) 3-phenylamino propoxy phenyl trifunctional epoxy resin was identified and confirmed using FTIR and NMR spectroscopy. Moreover, viscosity, rheological, and thermal analyses of the TER and its nanocomposite were examined using an Ubbelhod VB-1423 capillary viscosimeter, RHM01RD HAAKE rheometer, and thermogravimetric analysis, respectively.

\section{Materials and Methods}

\subsection{Synthesis of trifunctional epoxy resin (TER).}

Trigycidyl of para aminophenol (TGPAP), aniline (98\%), epichlorohydrin (99\%), triethylamine (97\%), methylene dianiline (99\%), zinc oxide, and methanol were purchased by Aldrich Chemical Company and used without any other purification. Trifunctional epoxy resin, namely triglycidyl ether N,N bis (3-phenylamino propyl) 3-phenylamino propoxy phenyl (TER) was synthesis in two steps according to the procedure reported in many works of literature [39-41]. In the first step, $5.5 \times 10^{-3} \mathrm{~mol}$ of aniline as the nucleophilic group was added to $6.54 \times 10^{-3} \mathrm{~mol}$ of TGPAP with magnetic stirring for $6 \mathrm{~h}$ at $80{ }^{\circ} \mathrm{C}$ to open the epoxy groups. During the second step, $5.5310^{-3} \mathrm{~mol}$ of epichlorohydrin was added to the intermediate product by condensation reaction with magnetic stirring for $4 \mathrm{~h}$ at $70{ }^{\circ} \mathrm{C}$. Besides, $9.85 \times 10^{-3} \mathrm{~mol}$ of triethylamine as a basis was added to the reaction mixture with magnetic stirring for $3 \mathrm{~h}$ at 40 ${ }^{\circ} \mathrm{C}$. TER epoxy resin was obtained by removing the secondary products using the rotary evaporator. Finally, TER was obtained with a yield of $92 \%$ (Figure 1).

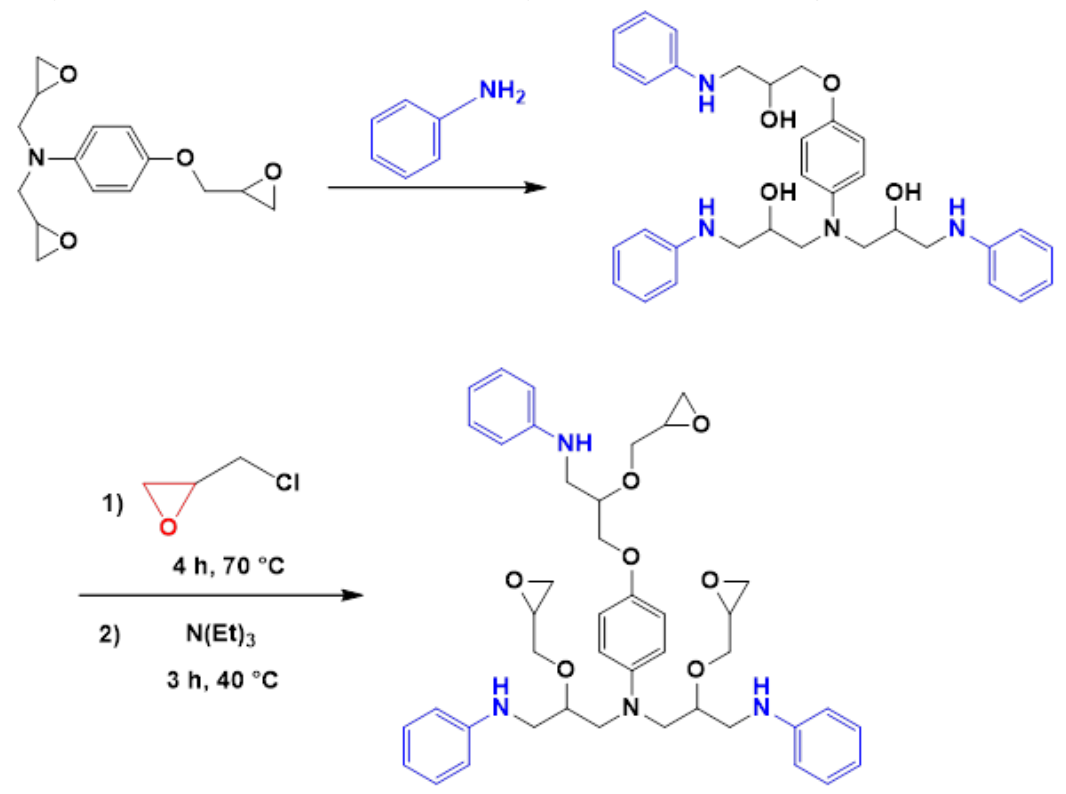

Figure 1.Synthesis of trifunctional epoxy resin (TER).

\subsection{Curing of trifunctional epoxy resin (TER).}

TER was cured using methylene dianiline (MDA) as a curing agent to form a threedimensional material (Figure 2). Then, the four hydrogens atoms of methylene dianiline react 
with the oxirane groups of TER by the condensation reaction. Besides, MDA and TER are curing in the oven at $80^{\circ} \mathrm{C}$. Moreover, TER was mixed with MDA to provide a single-phase $[42,43]$. Further, the development specimens were placed in a geometrically designed mold at $70^{\circ} \mathrm{C}$ for $24 \mathrm{~h}$. Finally, we proceeded to develop the nanocomposite using the identical procedure above in the hardening of TER with MDA and zinc oxide $(\mathrm{ZnO})$ as charge at different percentages $(0,0.5,1$, and $2 \%)$ [20].

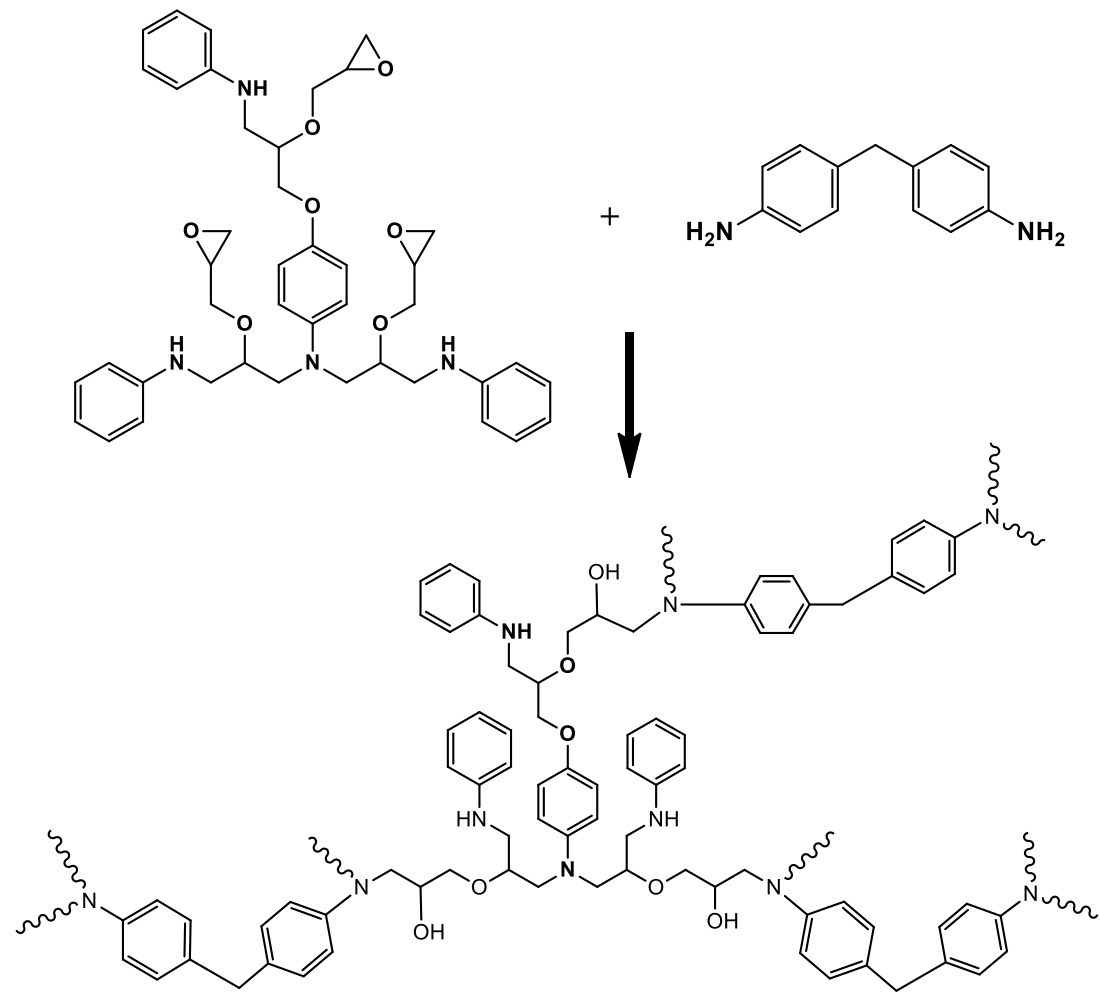

Figure 2.TER crosslinking using MDA.

\subsection{Fourier-transform infrared spectroscopy.}

The infrared spectrometer used is BRUKER Fourier transformed infrared spectrometer (FTIR). The light beam passes through the specimen to a thickness of about $2 \mu \mathrm{m}$. The analysis is carried out between $4000 \mathrm{~cm}^{-1}$ and $600 \mathrm{~cm}^{-1}$.

\subsection{Nuclear magnetic resonance.}

The nuclear magnetic resonance $\left({ }^{1} \mathrm{H}\right.$ NMR and $\left.{ }^{13} \mathrm{C} \mathrm{NMR}\right)$ analysis was obtained using an apparatus of Bruker AVANCE 300 by dissolving the product in DMSO. The chemical displacements are presented in ppm. The letter s, d, t, q, and $\mathrm{m}$ denote singlet, doublet, triplet, quadruplet, and multiplet, respectively.

\subsection{Rheological analysis.}

The viscosimetric and rheological properties of epoxy resin and its composites were analyzed using capillary viscosimeter VB-1423 of the Ubbelohd and RHM01-RD HAAKE rheometer (HAAKE MARS), respectively.

\subsection{Thermogravimetric analysis.}

To realize our study, which deals with the degradation of elaborated epoxy resin and its nanocomposites, we employed the thermogravimetric analysis method (ATG). Measurements 
of the kinetics of degradation by mass loss were carried by using a SETARAM TAG 24S. The heating rate is $10{ }^{\circ} \mathrm{C} / \mathrm{min}$, and the range of the measurement temperature is 0 to $600{ }^{\circ} \mathrm{C}$.

\section{Results and Discussion}

\subsection{FTIR and NMR characterization.}

Fourier transform infrared (FTIR) and nuclear magnetic resonance $\left({ }^{1} \mathrm{H}\right.$ NMR and ${ }^{13} \mathrm{C}$ NMR) analyses were realized to confirm the chemical structure of the triglycidyl ether $\mathrm{N}, \mathrm{N}$ bis (3-phenylamino propyl) 3-phenylamino propoxy phenyltrifunctional epoxy resin. FTIR, ${ }^{1} \mathrm{H}$ NMR, and ${ }^{13} \mathrm{C}$ NMR spectrums of TER are displayed in Figures 3, 4, and 5. Then, the different bands and chemical shift results obtained of the trifunctional epoxy resin are reported below.

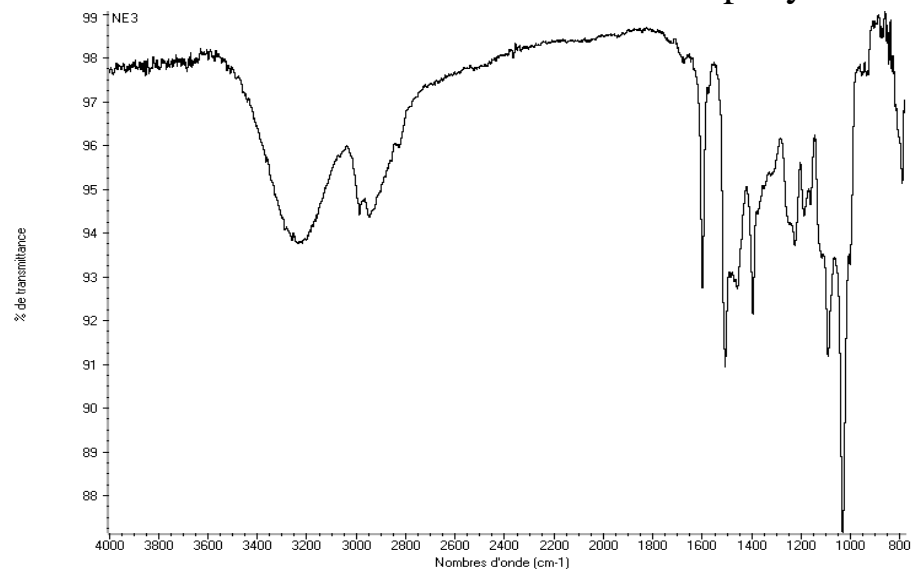

Figure 3. IR spectra of TER.

FTIR ( $\mathbf{c m}^{-1}$ ): 3240 (band of N-H), 2900 (band of $\mathrm{CH}_{2}$ linked to oxygen), 1450-1580 (band of N-C linked to aromatic rings), 1400 (band of C-N-Ar), 1030 (band of aromatic C-H), and 820 (band of oxirane group).

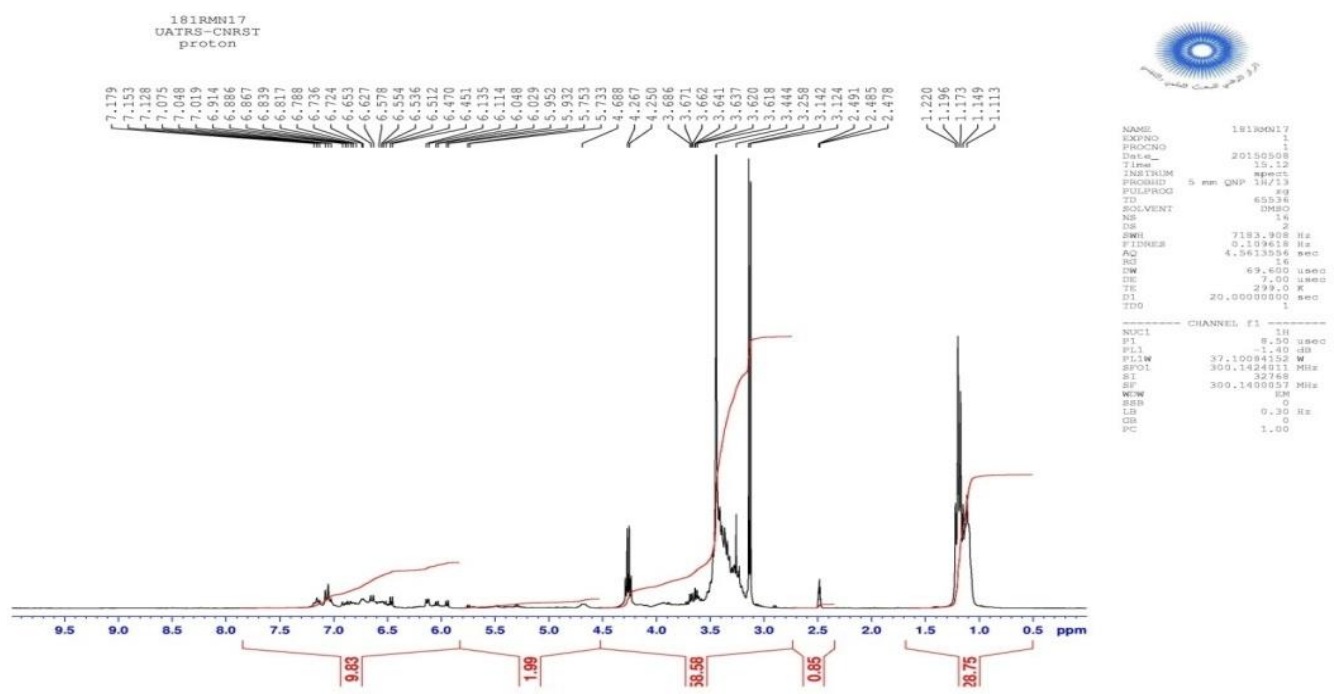

Figure 4. ${ }^{1} \mathrm{H}$ NMR spectra of TER.

${ }^{1} \mathbf{H}$ NMR (ppm): 1.2 (solvent); 2.5 (d, $6 \mathrm{H}, \mathrm{CH}_{2}$ of oxirane group); 3 (m, 3H, CH of oxirane group); $3.3\left(\mathrm{~m}, 3 \mathrm{H}, \mathrm{CH}\right.$ linked to $\mathrm{CH}$ aliphatic); $3.5\left(\mathrm{~d}, 6 \mathrm{H}, \mathrm{CH}_{2}\right.$ linked to oxirane group and nitrogen); 3.7 (d, $6 \mathrm{H}, \mathrm{CH}_{2}$ linked to phenylamino); 4.3 (s, $3 \mathrm{H}, \mathrm{NH}$ linked to phenyl); 6-6.3 (m, $15 \mathrm{H}, \mathrm{CH}$ aromatic), $6.6(\mathrm{~d}, 2 \mathrm{H}, \mathrm{CH}$ aromatic of $\mathrm{N}$ in ortho position), and 7.2 (d, 2 $\mathrm{H}, \mathrm{CH}$ aromatic of $\mathrm{N}$ in meta position). 


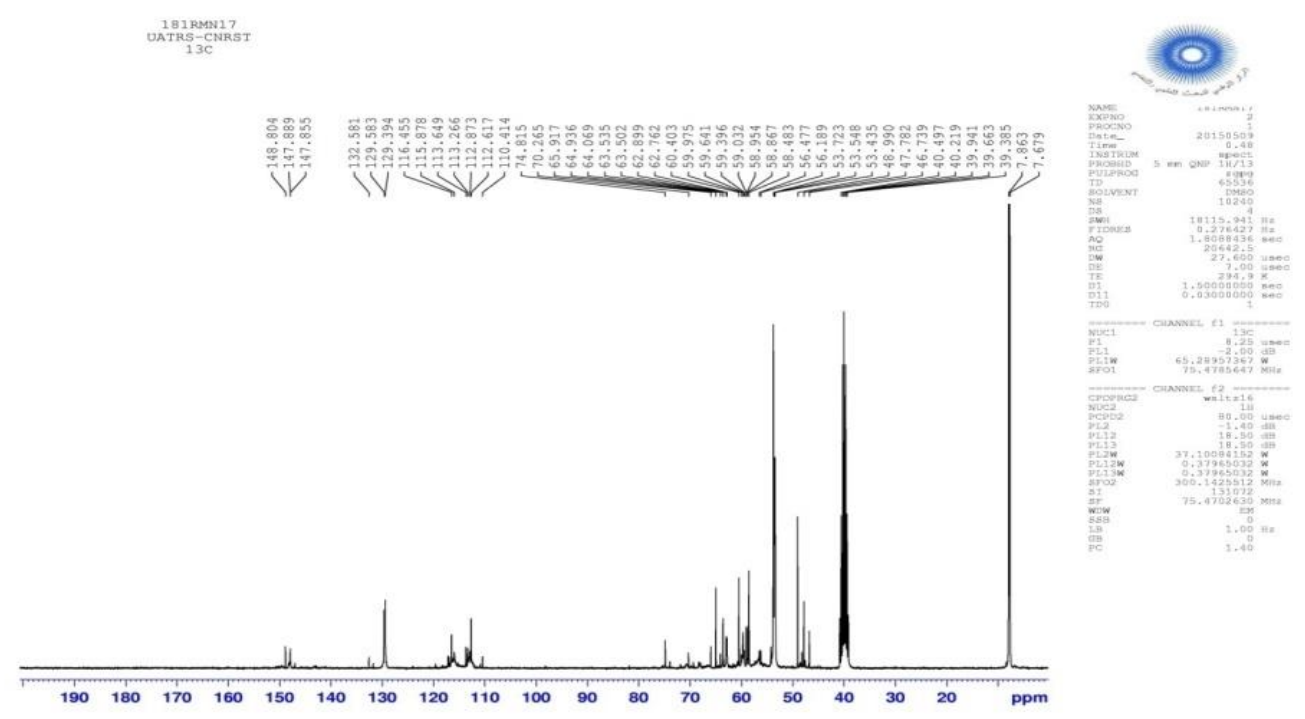

Figure 5. ${ }^{13} \mathrm{C}$ NMR spectra of TER.

${ }^{13} \mathbf{C}$ NMR (ppm): 40 (solvent); 47 (s, $\mathrm{CH}_{2}$ of oxirane); 49 (s, $\mathrm{CH}_{2}$ linked of aminophenyl); 55 (s, $\mathrm{CH}$ of oxirane); 58 (s, $\mathrm{CH}_{2}$ linked to $\mathrm{N}$ ); 60 (s, $\mathrm{CH}_{2}$ linked to oxirane and oxygen); 65 (s, $\mathrm{CH}_{2}$ linked to oxirane and oxygen); 68 (s, $\mathrm{CH}_{2}$ linked to phenoxy); 70 (s, $\mathrm{CH}$ linked to methoxy oxirane); 70 (s, $\mathrm{CH}$ linked to methoxy oxirane); 75 (s, $\mathrm{CH}$ linked to methoxyphenyl); 112 (s, aromatic $\mathrm{CH}$ in ortho position to nitrogen); 115 (s, aromatic $\mathrm{CH}$ in meta position to nitrogen); 130 (s, aromatic $\mathrm{CH}$ in para position to nitrogen); 147 (s, aromatic carbon bound to $\mathrm{N}$ ), and 149 (s, aromatic carbon bound to NH).

\subsection{Viscosity study.}

Figure 6 display the variation of viscosity of the (TER/Ethanol) system according to the temperature at various weight percentages $(5,10,15$, and $20 \%)$.

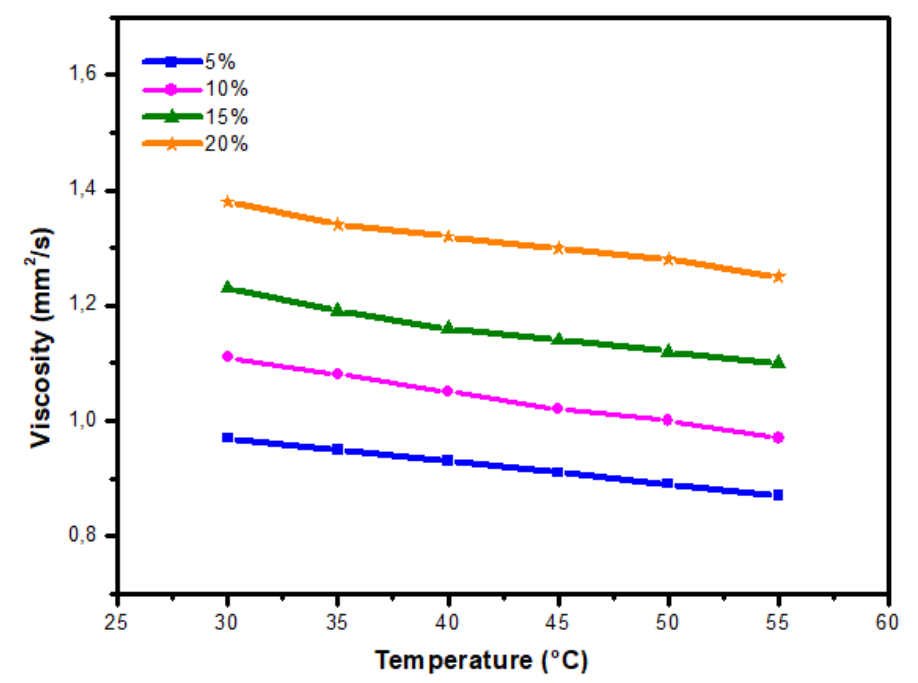

Figure 6. Viscosity of the TER/Ethanol system according to the temperature at various weight percentages.

The viscosity of the (TER/Ethanol) system increases with the increase in the weight percentage of trifunctional epoxy resin at each temperature. This augmentation can be explained by the increase in the molecular mass of the (TER/Ethanol) system [44-46]. This due to the increase in the (TER/Ethanol) system's density by a strong interaction between the bonds 
of the epoxy resin employed. As the temperature increase suggests, the viscosity of (TER/Ethanol) system is decreasing. This decrease in viscosity indicates that the density is becoming low. Therefore, the heat is given by the apparatus feebleness the interaction between the bonds of TER. Further, the viscosity changes from a viscous state to a liquid state.

\subsection{Rheological properties.}

Rheological properties are interesting properties that affect the processing of the formulation of the nanocomposite. Variation of storage modulus $G^{\prime}$ and loss modulus $G^{\prime \prime}$ versus frequency for nanocomposite pure (TER/MDA) and formulated nanocomposites (TER/MDA/ZnO) with various percentages of zinc oxide are plotted in Figure 7 and 8.

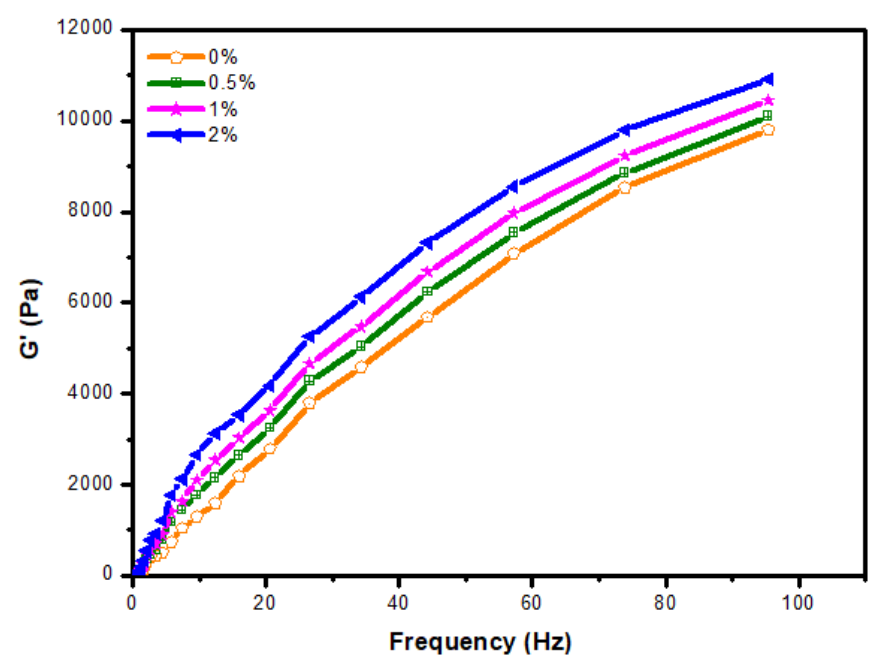

Figure 7. Storage modulus $\mathrm{G}^{\prime}$ for TER/MDA/ZnO according to frequency.

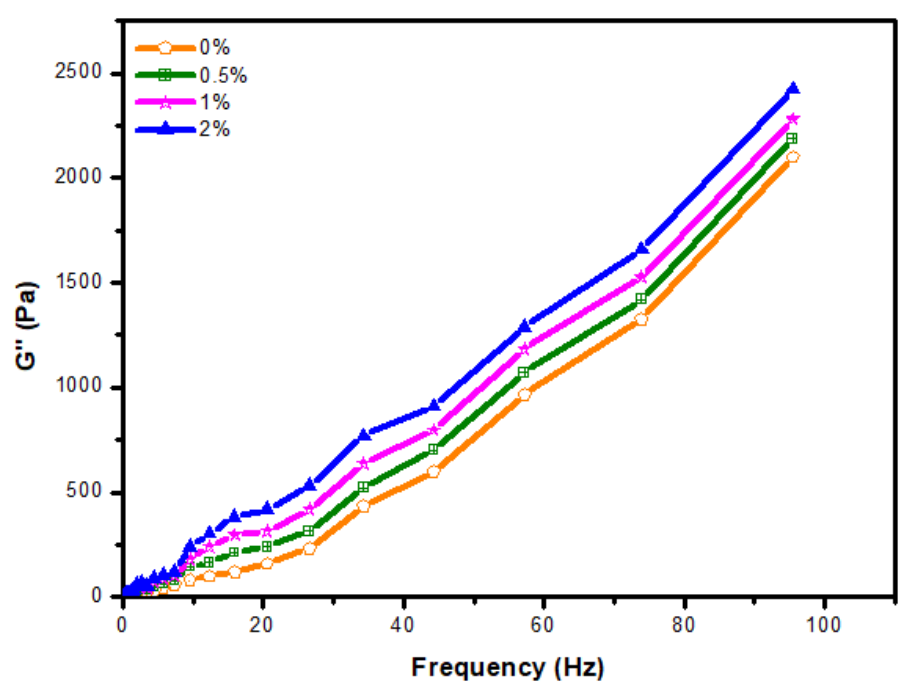

Figure 8. Loss modulus $\mathrm{G}^{\prime \prime}$ for TER/MDA/ZnO according to frequency.

Storage modulus $\mathrm{G}^{\prime}$ and loss modulus $\mathrm{G}^{\prime \prime}$ values of different nanocomposites increase with increasing zinc oxide as charge [47, 48]. The loss modulus $\mathrm{G}^{\prime \prime}$ was significantly lower than the storage modulus $\mathrm{G}^{\prime}$ over the entire frequency examined for nanocomposite crosslinked by methylene dianiline and formulated with different zinc oxide percentages. The storage modulus $\mathrm{G}^{\prime}$ of all prepared nanocomposite increases with an increase in $\mathrm{ZnO}$ percentages [40, 49]. This result indicates the progressive curing of the three-dimensional network. The rheological behaviors were highly correlated with the formulation of the nanocomposites. 


\subsection{Thermal properties.}

The thermal properties of the TER crosslinked by methylene dianiline as a hardener and formulated with zinc oxide $(\mathrm{ZnO})$ as a filler (TER/MDA/ZnO) at various percentages were measured by thermogravimetric analysis (TGA). The TGA plots are displayed in Figure 9. The TGA results are depicted in Table $1\left(\mathrm{~T}_{\mathrm{d}}, \mathrm{T}_{50}\right.$ and $\mathrm{R}\left(500{ }^{\circ} \mathrm{C}\right)$. The temperature at which decomposition begins, decomposition temperature at $50 \%$ of weight loss, and the residual amount at $500{ }^{\circ} \mathrm{C}$, respectively). The result in Table 1 indicates that the residual amount of the formulated nanocomposite (TER/MDA/ZnO) is a higher value compared with the TER/MDA pure [50-54]. The reason is that zinc oxide does not decompose below $500{ }^{\circ} \mathrm{C}$. Further, the higher the zinc oxide's mass ratio in the nanocomposite (TER/MDA/ZnO) elevates, the residual amount elevates consequently. All TGA plots display one peak, indicating thermal degradation of the elaborated nanocomposites [55-57]. Then, the temperature peak of the nanocomposite pure (TER/MDA) is $220^{\circ} \mathrm{C}$. The weight loss of the (TER/MDA) begins from $220{ }^{\circ} \mathrm{C}$ and loses all its weight at $409{ }^{\circ} \mathrm{C}$. However, the temperature peak of the formulated nanocomposite (TER/MDA/ZnO) is $268^{\circ} \mathrm{C}$. The weight loss of the (TER/MDA/ZnO) starts from $268{ }^{\circ} \mathrm{C}$ and loses all its weight at $477{ }^{\circ} \mathrm{C}$. Also, the temperature peak of the formulated nanocomposite (TER/MDA/ZnO) is higher than that of nanocomposite pure (TER/MDA) [20, 58, 59].

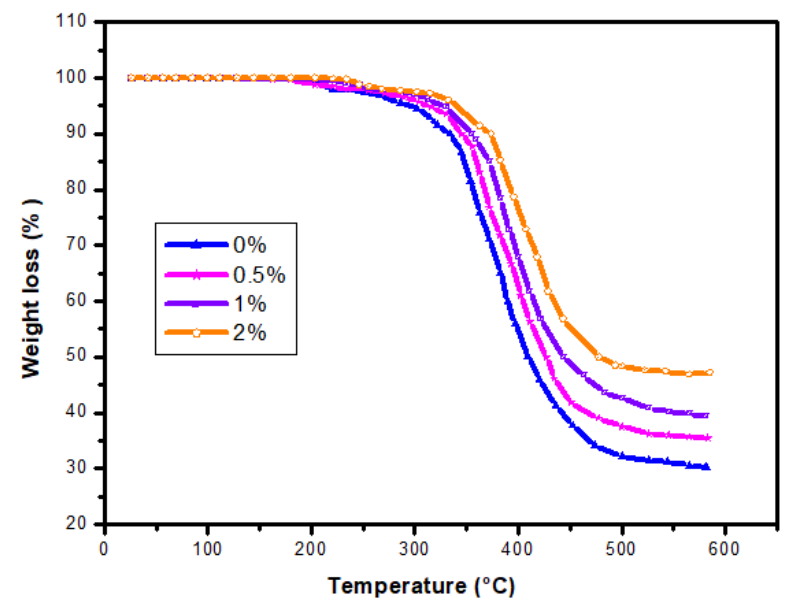

Figure 9. TGA plots of TER/MDA and TER/MDA/ZnO.

Table 1. TGA data of TER/MDA and TER/MDA/ZnO.

\begin{tabular}{l|l|l|l|l|l} 
Nanocomposites & $\mathbf{T}_{\mathbf{d}}\left({ }^{\circ} \mathbf{C}\right)$ & $\mathbf{T}_{\mathbf{1 0}}\left({ }^{\circ} \mathbf{C}\right)$ & $\mathbf{T}_{\mathbf{5 0}}\left({ }^{\circ} \mathbf{C}\right)$ & $\mathbf{S}_{\mathbf{d r}}\left({ }^{\circ} \mathbf{C}\right)$ & $\mathbf{R}(\boldsymbol{\%})\left(\mathbf{5 0 0}{ }^{\circ} \mathbf{C}\right)$ \\
\hline TER/MDA/0\% ZnO & 220 & 333 & 409 & 344 & 32.5 \\
\hline TER/MDA/0.5\% ZnO & 235 & 345 & 427 & 356 & 37.6 \\
\hline TER/MDA/1\% ZnO & 255 & 357 & 443 & 368 & 42.5 \\
\hline TER/MDA/2\% ZnO & 268 & 374 & 477 & 381 & 48.5
\end{tabular}

\section{Conclusions}

In this study, we have developed and investigated the triglycidyl ether N,N bis (3phenylamino propyl) 3-phenylamino propoxy phenyl (TER) trifunctional epoxy resin. Epoxy resin (TER) was identified using FTIR and NMR spectroscopy. Viscosimetric behaviors of TER/Ethanol decreased with an increase in temperature. Further, TER/MDA/ZnO curing by methylene dianiline and formulated by zinc oxide were investigated as potential nanocomposite for rheological and thermogravimetric analysis. Then, storage modulus and the loss modulus for varying nanocomposites elevate with both the elevate into zinc oxide and frequency. This could explain that the charge employed incorporated into nanocomposites is very well 
formulated. The thermogravimetric analysis data confirm the amelioration of the thermal properties of varying nanocomposites formulated at different percentages of $\mathrm{ZnO}$.

\section{Funding}

This research received no external funding.

\section{Acknowledgments}

Many thanks to Prof. Ahmed ELHARFI at University IbnTofail, Morocco. Many thanks to Doctor Rachid HSISSOU, who collaborated to the success of this paper. All evaluators of this work gave enough time to review it with their excellent remarks and questions to give it some value.

\section{Conflicts of Interest}

The authors declare no conflict of interest.

\section{References}

1. Yao, W.; Zhang, Q.; Qi, F.; Zhang, J.; Liu, K.; Li, J.; Chen, W.; Du, Y.; Jin, Y.; Liang, Y.; Liu, N. Epoxy containing solid polymer electrolyte for lithium ion battery. Electrochim. Acta 2019, 318, 302-313, https://doi.org/10.1016/j.electacta.2019.06.069.

2. Ou, B.; Chen, M.; Guo, Y.; Kang, Y.; Guo, Y.; Zhang, S.; Yan, J.; Liu, Q.; Li, D. Preparation of novel marine antifouling polyurethane coating materials. Polym. Bull. 2018, 75, 5143-5162, https://doi.org/10.1007/s00289-018-2302-5.

3. Liang, Y.; Liu, B.; Zhang, B.; Liu, Z.; Liu, W. Effects and mechanism of filler surface coating strategy on thermal conductivity of composites: A case study on epoxy/SiO2-coated BN composites. Int. J. Heat Mass Transfer 2021, 164, 120533, https://doi.org/10.1016/j.ijheatmasstransfer.2020.120533.

4. Lin, T.A.; Lin, J.-H.; Bao, L. A study of reusability assessment and thermal behaviors for thermoplastic composite materials after melting process: Polypropylene/ thermoplastic polyurethane blends. Journal of Cleaner Production 2021, 279, 123473, https://doi.org/10.1016/j.jclepro.2020.123473.

5. Zoukrami, F.; Haddaoui, N.; Sclavons, M.; Devaux, J.; Vanzeveren, C. Rheological properties and thermal stability of compatibilized polypropylene/untreated silica composites prepared by water injection extrusion process. Polym. Bull. 2018, 75, 5551-5566, https://doi.org/10.1007/s00289-018-2344-8.

6. Hsissou, R.; Benhiba, F.; Dagdag, O.; El Bouchti, M.; Nouneh, K.; Assouag, M.; Briche, S.; Zarrouk, A.; Elharfi, A. Development and potential performance of prepolymer in corrosion inhibition for carbon steel in $1.0 \mathrm{M} \mathrm{HCl}$ : Outlooks from experimental and computational investigations. J. Colloid Interface Sci. 2020.

7. Safaie, B.; Youssefi, M.; Rezaei, B. Rheological behavior of polypropylene/carbon quantum dot nanocomposites: the effects of particles size, particles/matrix interface adhesion, and particles loading. Polym. Bull. 2019, 76, 4335-4354, https://doi.org/10.1007/s00289-018-2611-8.

8. Dagdag, O.; Safi, Z.; Hsissou, R.; Erramli, H.; El Bouchti, M.; Wazzan, N.; Guo, L.; Verma, C.; Ebenso, E.E.; El Harfi, A. Epoxy pre-polymers as new and effective materials for corrosion inhibition of carbon steel in acidic medium: Computational and experimental studies. Sci. Rep. 2019, 9, 11715, https://doi.org/10.1038/s41598-019-48284-0.

9. Hsissou, R.; Bekhta, A.; Dagdag, O.; El Bachiri, A.; Rafik, M.; Elharfi, A. Rheological properties of composite polymers and hybrid nanocomposites. Heliyon 2020, 6, e04187, https://doi.org/10.1016/j.heliyon.2020.e04187.

10. Hsissou, R.; Benhiba, F.; Abbout, S.; Dagdag, O.; Benkhaya, S.; Berisha, A.; Erramli, H.; Elharfi, A. Trifunctional epoxy polymer as corrosion inhibition material for carbon steel in $1.0 \mathrm{M} \mathrm{HCl}$ : MD simulations, DFT and complexation computations. Inorg. Chem. Commun. 2020, 115, 107858, https://doi.org/10.1016/j.inoche.2020.107858.

11. El Gouri, M.; El-Harfi, A. Modifications chimiques de l'hexachlorocyclotriphosphazène-Préparation de retardateurs de flame et de matériaux polymères ignifuges écologiques (Chemical modification of 
hexachlorocyclotriphosphazene-Preparation of flame retardants and ecological flame retardant polymers). Journal of Materials and Environmental Science 2012, 3, 17-33.

12. Li, S.; Yao, Y. Synergistic improvement of epoxy composites with multi-walled carbon nanotubes and hyperbranched polymers. Composites Part B: Engineering 2019, 165, 293-300, https://doi.org/10.1016/j.compositesb.2018.11.122.

13. Zotti, A.; Zuppolini, S.; Borriello, A.; Zarrelli, M. The effect of glassy and rubbery hyperbranched polymers as modifiers in epoxy aeronautical systems. Composites Part B: Engineering 2019, 169, 88-95, https://doi.org/10.1016/j.compositesb.2019.04.006.

14. Jia, S.; Wang, F.; Xu, B.; Yan, W. A developed energy-dependent model for studying thermal shock damage and phase transition of composite reinforced panel subjected to lightning strike. European Journal of Mechanics - A/Solids 2021, 85, 104141, https://doi.org/10.1016/j.euromechsol.2020.104141.

15. Zhang, S.; Li, Z.; Guo, Y.; Cai, L.; Manikandan, P.; Zhao, K.; Li, Y.; Pol, V.G. Room-temperature, highvoltage solid-state lithium battery with composite solid polymer electrolyte with in-situ thermal safety study. Chem. Eng. J. 2020, 400, 125996, https://doi.org/10.1016/j.cej.2020.125996.

16. Yin, H.; Gao, S.; Cai, Z.; Wang, H.; Dai, L.; Xu, Y.; Liu, J.; Li, H. Experimental and numerical study on thermal protection by silica aerogel based phase change composite. Energy Reports 2020, 6, 1788-1797, https://doi.org/10.1016/j.egyr.2020.06.026.

17. Haoliang, T.; Changliang, W.; Mengqiu, G.; Yongjing, C.; Junguo, G.; Zhihui, T.; Yi, L.; Cong, S.; Hao, W.; Guo, J.; Shicheng, W. Study on process and performance of thermal protective coating on polyimide resin matrix composite. Ceram. Int. 2020, 46, 12744-12758, https://doi.org/10.1016/j.ceramint.2020.02.043.

18. Hsissou, R.; Abbout, S.; Seghiri, R.; Rehioui, M.; Berisha, A.; Erramli, H.; Assouag, M.; Elharfi, A. Evaluation of corrosion inhibition performance of phosphorus polymer for carbon steel in [1 $\mathrm{M}] \mathrm{HCl}$ : Computational studies (DFT, MC and MD simulations). Journal of Materials Research and Technology 2020, 9, 2691-2703, https://doi.org/10.1016/j.jmrt.2020.01.002.

19. El-Aouni, N.; Benabida, A.; Cherkaoui, M.; Elharfi, A. A New Epoxy Resin Based Organic Molecule as an Effective Inhibitor of Mild Steel Corrosion in a Sulfuric Acid Medium. Journal of Chemical Technology \& Metallurgy 2018, 53, 878-890.

20. El-Aouni, N.; Hsissou, R.; Azzaoui, J.E.; Bouchti, M.E.; Elharfi, A. Synthesis rheological and thermal studies of epoxy polymer and its composite. Chemical Data Collections 2020, 30, 100584, https://doi.org/10.1016/j.cdc.2020.100584.

21. Hsissou, R.; Benhiba, F.; Echihi, S.; Benkhaya, S.; Hilali, M.; Berisha, A.; Briche, S.; Zarrouk, A.; Nouneh, K.; Elharfi, A. New epoxy composite polymers as a potential anticorrosive coatings for carbon steel in $3.5 \%$ $\mathrm{NaCl}$ solution: Experimental and computational approaches. Chemical Data Collections 2021, 31, 100619, https://doi.org/10.1016/j.cdc.2020.100619.

22. Zhang, L.F.; Gao, R.; Hou, J.; Zhao, B.L.; Sun, M.; Hao, T.; Xie, Z.M.; Liu, R.; Wang, X.P.; Fang, Q.F.; Liu, C.S. Study on thermal stability and irradiation response of copper/iron nano-multilayer composite fabricated by cross accumulative roll bonding. J. Nucl. Mater. 2021, 543, 152548, https://doi.org/10.1016/j.jnucmat.2020.152548.

23. Cheng, K.-C.; Yu, S.-Y.; Chiu, W.-Y. Thermal properties of side-chain phosphorus-containing epoxide cured with amine. J. Appl. Polym. Sci. 2002, 83, 2741-2748, https://doi.org/10.1002/app.10161.

24. Castell, P.; Serra, A.; Galià, M. Liquid-crystalline thermosets from liquid-crystalline epoxy resins containing bisazomethinebiphenylene mesogens in the central core: Copolymerization with a nonmesomorphic epoxy resin. J. Polym. Sci., Part A: Polym. Chem. 2004, 42, 3631-3643, https://doi.org/10.1002/pola.20254.

25. Sadagopan, K.; Ratna, D.; Samui, A.B. Synthesis and characterization of liquid-crystalline epoxy and its blend with conventional epoxy. J. Polym. Sci., Part A: Polym. Chem. 2003, 41, 3375-3383, https://doi.org/10.1002/pola.10923.

26. Chruściel, J.J.; Leśniak, E. Modification of epoxy resins with functional silanes, polysiloxanes, silsesquioxanes, silica and silicates. Prog. Polym. Sci. 2015, 41, 67-121, https://doi.org/10.1016/j.progpolymsci.2014.08.001.

27. Grich, M.; El Gouri, M.; Ziraoui, R.; Rami, N.; Meghraoui, H.; Cherkaoui, O.; El Harfi, A. Thermal and rheological study of blended carbon nanotube/epoxy resin nanocomposites. J. Mater. Environ. Sci 2014, 5, 374-379.

28. Chen, M.; Liang, X.; Hu, W.; Zhang, L.; Zhou, L.; Zhang, C.; Wang, J.; Meng, C.; Fang, J.; Yang, H. Precipitation polymerization in liquid crystals to prepare uniform epoxy microspheres. Polymer 2018, 154, 291-297, https://doi.org/10.1016/j.polymer.2018.09.006. 
29. Hsissou, R.; Benzidia, B.; Hajjaji, N.; Elharfi, A. Elaboration and electrochemical studies of the coating behavior of a new nanofunctional epoxy polymer on E24 steel in 3.5\% NaCl. Portugaliae Electrochimica Acta 2018, 36, 259-270, http://dx.doi.org/10.4152/pea.201804259.

30. Mahadeva Raju, G.K.; Madhu, G.M.; Ameen Khan, M.; Dinesh Sankar Reddy, P. Characterizing and Modeling of Mechanical Properties of Epoxy Polymer Composites Reinforced with Fly ash. Materials Today: Proceedings 2018, 5, 27998-28007, https://doi.org/10.1016/j.matpr.2018.10.040.

31. Hsissou, R.; Bekhta, A.; Elharfi, A.; Benzidia, B.; Hajjaji, N. Theoretical and electrochemical studies of the coating behavior of a new epoxy polymer: hexaglycidyl ethylene of methylene dianiline (HGEMDA) on E24 steel in $3.5 \% \mathrm{NaCl}$. Portugaliae Electrochimica Acta 2018, 36, 101-117, http://dx.doi.org/10.4152/pea.201802101.

32. Srinivasaraonaik, B.; Singh, L.P.; Sinha, S.; Tyagi, I.; Rawat, A. Studies on the mechanical properties and thermal behavior of microencapsulated eutectic mixture in gypsum composite board for thermal regulation in the buildings. Journal of Building Engineering 2020, 31, 101400, https://doi.org/10.1016/j.jobe.2020.101400.

33. El Gouri, M.; El Bachiri, A.; Hegazi, S.E.; Rafik, M.; El Harfi, A. Thermal degradation of a reactive flame retardant based on cyclotriphosphazene and its blend with DGEBA epoxy resin. Polym. Degradation Stab. 2009, 94, 2101-2106, https://doi.org/10.1016/j.polymdegradstab.2009.08.009.

34. Park, H.; Kim, B.; Choi, J.; Cho, M. Influences of the molecular structures of curing agents on the inelasticdeformation mechanisms in highly-crosslinked epoxy polymers. Polymer 2018, 136, 128-142, https://doi.org/10.1016/j.polymer.2017.12.055.

35. Ren, X.-J.; Dai, Y.-J.; Gou, J.-J.; Tao, W.-Q. Numerical study on thermal contact resistance of 8-harness satin woven pierced composite. International Journal of Thermal Sciences 2021, 159, 106584, https://doi.org/10.1016/j.ijthermalsci.2020.106584.

36. Yang, H.; Cai, F.; Luo, Y.; Ye, X.; Zhang, C.; Wu, S. The interphase and thermal conductivity of graphene oxide/butadiene-styrene-vinyl pyridine rubber composites: A combined molecular simulation and experimental study. Composites Sci. Technol. $\quad$ 2020, https://doi.org/10.1016/j.compscitech.2019.107971.

37. Chen, J.; Liu, B.; Gao, X. Thermal properties of graphene-based polymer composite materials: A molecular dynamics study. Results in Physics 2020, 16, 102974, https://doi.org/10.1016/j.rinp.2020.102974.

38. Tripathy, S.; Jali, P.; Parida, C.; Pradhan, C. Study on biodegradability and thermal behaviour of composites using poly lactic acid and gamma-irradiated fibres of Luffa cylindrica. Chemosphere 2020, 261, 127684, https://doi.org/10.1016/j.chemosphere.2020.127684.

39. Ziraoui, R.; Grich, M.; Meghraoui, H.; Elgouri, M.; Mouada, A.; Fetouaki, S.; Elharfi, A. Study of thermal, mechanical and dielectrical properties of a composite material based on DGEBA flexibilized by CTBN. in Ann. Chim. Sci. Mat.2010, 35, 99-112.

40. Hsissou, R.; Berradi, M.; El Bouchti, M.; El Bachiri, A.; El Harfi, A. Synthesis characterization rheological and morphological study of a new epoxy resin pentaglycidyl ether pentaphenoxy of phosphorus and their composite (PGEPPP/MDA/PN). Polym. Bull. 2019, 76, 4859-4878, https://doi.org/10.1007/s00289-0182639-9.

41. Hsissou, R.; Abbout, S.; Safi, Z.; Benhiba, F.; Wazzan, N.; Guo, L.; Nouneh, K.; Briche, S.; Erramli, H.; Ebn Touhami, M.; Assouag, M.; Elharfi, A. Synthesis and anticorrosive properties of epoxy polymer for CS in $[1 \mathrm{M}] \mathrm{HCl}$ solution: Electrochemical, AFM, DFT and MD simulations. Construction and Building Materials 2020, 121454, doi:https://doi.org/10.1016/j.conbuildmat.2020.121454.

42. Nayak, R.K.; Ray, B.C. Influence of seawater absorption on retention of mechanical properties of nanoTiO2 embedded glass fiber reinforced epoxy polymer matrix composites. Archives of Civil and Mechanical Engineering 2018, 18, 1597-1607, https://doi.org/10.1016/j.acme.2018.07.002.

43. Hsissou, R.; Benzidia, B.; Hajjaji, N.; Elharfi, A. Elaboration and electrochemical studies of the coating behavior of a new pentafunctional epoxy polymer (pentaglycidyl ether pentabisphenol phosphorus) on E24 carbon steel in $3.5 \% \mathrm{NaCl}$. Journal of Chemical Technology and Metallurgy 2018, 53, 898-905.

44. Hsissou, R.; El Bouchti, M.; Elharfi, A. Elaboration and viscosimetric, viscoelastic and rheological studies of a new hexafunctional polyepoxide polymer: Hexaglycidyl Ethylene of Methylene Dianiline. J. Mater. Environ. Sci 2017, 8, 4349-4361.

45. Hsissou, R.; Bekhta, A.; Elharfi, A. Viscosimetric and rheological studies of a new trifunctional epoxy prepolymer with noyan ethylene: Triglycidyl Ether of Ethylene of Bisphenol A (TGEEBA). J. Mater. Environ. Sci 2017, 8, 603-610. 
46. Metalwala, Z.; Khoshroo, K.; Rasoulianboroujeni, M.; Tahriri, M.; Johnson, A.; Baeten, J.; Fahimipour, F.; Ibrahim, M.; Tayebi, L. Rheological properties of contemporary nanohybrid dental resin composites: The influence of preheating. Polym. Test. 2018, https://doi.org/10.1016/j.polymertesting.2018.10.013.

47. Hsissou, R.; Elharfi, A. Rheological behavior of three polymers and their hybrid composites (TGEEBA/MDA/PN), (HGEMDA/MDA/PN) and (NGHPBAE/MDA/PN). Journal of King Saud University - Science 2020, 32, 235-244, https://doi.org/10.1016/j.jksus.2018.04.030.

48. Zhang, Y.; Cui, L.; Xu, H.; Feng, X.; Wang, B.; Pukánszky, B.; Mao, Z.; Sui, X. Poly(lactic acid)/cellulose nanocrystal composites via the Pickering emulsion approach: Rheological, thermal and mechanical properties. Int. J. Biol. Macromol. 2019, 137, 197-204, https://doi.org/10.1016/j.ijbiomac.2019.06.204.

49. Liao, W.; Wang, G.; Liu, Z.; Xu, S.; Wang, Y.-Z. Rheological premonitory of nanoclay morphology on the mechanical characteristics of composite aerogels. Composites Part B: Engineering 2019, 173, 106889, https://doi.org/10.1016/j.compositesb.2019.05.100.

50. Liu, R.; Wang, X. Synthesis, characterization, thermal properties and flame retardancy of a novel nonflammable phosphazene-based epoxy resin. Polym. Degradation Stab. 2009, 94, 617-624, https://doi.org/10.1016/j.polymdegradstab.2009.01.008.

51. Lee, K.-H.; Bae, J.-S.; Yeum, J.H.; Park, J.; Sung, C.; Kim, J.; Oh, W. Thermal characteristics of epoxy composites with graphite and alumina. Thermochim. Acta 2019, 676, 115-119, https://doi.org/10.1016/j.tca.2019.04.004.

52. Hou, M.; Kong, X.; Li, H.; Yang, H.; Chen, W. Experimental study on the thermal performance of composite phase change ventilated roof. Journal of Energy Storage 2020, 102060, https://doi.org/10.1016/j.est.2020.102060.

53. Kumar, E.A.; Jivrakh, K.B.; Babu, K.S. Study of ammonia adsorption/desorption characteristics of $\mathrm{CaCl} 2-$ Expanded natural graphite composite for thermal energy storage. Thermal Science and Engineering Progress 2020, 20, 100752, https://doi.org/10.1016/j.tsep.2020.100752.

54. Melánová, K.; Beneš, L.; Zima, V.; Trchová, M.; Stejskal, J. Polyaniline-zirconium phosphonate composites: Thermal stability and spectroscopic study. J. Phys. Chem. Solids 2020, 147, 109634, https://doi.org/10.1016/j.jpcs.2020.109634.

55. Xu, C.; Miao, M.; Jiang, X.; Wang, X. Thermal conductive composites reinforced via advanced boron nitride nanomaterials. Composites Communications 2018, 10, 103-109, https://doi.org/10.1016/j.coco.2018.08.002.

56. Pan, J.; Bian, L. A physics investigation for influence of carbon nanotube agglomeration on thermal properties of composites. Mater. Chem. Phys. 2019, 236, 121777, https://doi.org/10.1016/j.matchemphys.2019.121777.

57. Saravanan, A.K.; Rajendra Prasad, A.; Muruganandam, D.; Saravanan, G.; Vivekanandan, S.; Sudhakar, M. Study on natural fiber composites of jute, pine apple and banana compositions percentage of weight basis for thermal resistance and thermal conductivity. Materials Today: Proceedings 2020, https://doi.org/10.1016/j.matpr.2020.04.662.

58. Wang, J.; Chen, Y.; Feng, Y.; Zhao, G.; Jian, X.; Huang, Q.; Yang, L.; Xu, J. Influence of porosity on anisotropic thermal conductivity of $\mathrm{SiC}$ fiber reinforced $\mathrm{SiC}$ matrix composite: A microscopic modeling study. Ceram. Int. 2020, 46, 28693-28700, https://doi.org/10.1016/j.ceramint.2020.08.029.

59. Im, D.S.; Hong, B.M.; Kim, M.H.; Park, W.H. Formation of human hair-Ag nanoparticle composites via thermal and photo-reduction: A comparison study. Colloids Surf. Physicochem. Eng. Aspects 2020, 600, 124995, https://doi.org/10.1016/j.colsurfa.2020.124995. 